\title{
The Effects of Online Interactions on the Relationship Between Learning-Related Anxiety and Intention to Persist Among E-Learning Students with Visual Impairment
}

Yunjin $\mathrm{Oh}^{1}$ and Soon Min Lee ${ }^{2}$

${ }^{1}$ Sejong Cyber University, ROK, ${ }^{2}$ Sejong Cyber University, ROK

\begin{abstract}
This study explored whether learning-related anxiety would negatively affect intention to persist with e-learning among students with visual impairment, and examined the roles of three online interactions in the relationship between learning-related anxiety and intention to persist with e-learning. For this study, a convenience sample of e-learning students with visual impairment was collected in Seoul, Korea over three weeks from November to December 2012. One hundred and three students completed the survey via email or telephone. The results showed significant associations between learning-related anxiety and intention to persist with e-learning. Three types of online interactions had different roles in and effects on the relationship between learning-related anxiety and intention to persist. Suggestions for improving intention to persist among students with visual impairment and for facilitating online communications were discussed.
\end{abstract}

Keywords: online interactions, learning-related anxiety, intention to persist, students with visual impairment

\section{Introduction}

Statistics from December 2013 show that South Korea has one of the highest internet penetration rates with $84.8 \%$ of the total population, that is, $41,571,196$ out of the $49,039,986$ total residents, utilizing the internet (Internet World Stats, 2014). According to the Korean Council of Cyber Universities, the number of cyber universities increased from nine, when the council was established in 2001, to 21 in 2015, totalling 99,108 students. Distance education has shifted from paper-based to web-based learning experiences, which provide opportunities to adult learners with disabilities who want to continue learning but find physically accessing campuses difficult. The shift has rapidly enhanced the right of students with disabilities to higher education. The number of students with disabilities increased from 1,523 in 2011 to 1,748 in 2013, that is, $2.2 \%$ of the 78,312 students at 21 cyber universities in South Korea identified as having a disability (Korean Council of Cyber Universities, 2013). Four hundred and nineteen students with visual impairment were reported to have enrolled in 17 South Korean cyber universities in 2012 (Korean Council for University College Education, 2013). The growing enrolment 
of students with visual impairment is expected to last due to the reasonable accommodations of webbased distance education, such as accessible study materials, flexibility in study time, and rehabilitation devices.

Although the benefits of web-based education meet many individuals' special needs, students with visual impairment can be challenged by their lack of computer skills (Calvin \& Freeburg, 2010) and their limited access to computers, the internet, and smart phones (Oh \& Lee, 2013) as well as the barriers related to the work-study balance, financial strain, a perceived lack of community (Drouin, 2008; Karamanos \& Gibbs, 2012), and other concerns. The high dropout rate of e-learning students has continued to be one of the most significant problems with web-based distance education (Lykourentzou, Giannoukos, Nikolopoulos, Mpardis, \& Loumos, 2009; Park \& Choi, 2009). According to the Information Service of Higher Education in Korea (2013), the average dropout rate at 17 Korean cyber universities was $18.15 \%$ in 2013. Moreover, the dropout issue is not restricted to students with visual impairment in cyber universities. Intention to persist is a critical factor in the dropout rates of all students in web-based distance education.

In the literature, a student's intention to persist with distance learning is considered a valid indicator of actual student persistence (Milem \& Berger, 1997) and is widely regarded as an indicator of successful web-based distance education (Campbell-Gibson, 1991). Intention to persist has been defined as the estimated likelihood of an individual's continued enrolment at an educational institution (Shin \& Chan, 2004). Research has focused on improving retention among e-learning students and on exploring the relationships between students' retention in web-based distance education and variables such as cognitive styles (Nachmias \& Shany, 2002), computer skills (Stein \& Wheaton, 2002), and online interactions (Moore, 2003). However, these results do not specifically reflect the retention of students with disabilities, especially students with visual impairment. Research on students with visual impairment in web-based distance education is lacking.

Anxiety can arise because of an individual's uncertainty about potential success and failure when he or she perceivably lacks control and when such outcomes are subjectively important to him or her (Pekrun, Goetz, Frenzel, Barchfeld, \& Perry, 2011). A student with visual impairment may feel anxious when taking online classes because assistive technology may not be up-to-date with the current online learning settings; consequently, these students may be unable to understand relevant information. Some studies (Lufi \& Awwad, 2013; Peleg, 2009) suggest that students with disabilities experience academic anxiety at higher rates than their counterparts without disabilities due to the former's academic difficulties, cognitive interference, negative academic self-concepts (Peleg, 2009), attention, concentration, and motivational and organizational difficulties (Heiman \& Precel, 2003).

Anxiety influences students' successful outcomes in web-based distance education, including their achievement and retention. A high level of anxiety can disrupt students' mental processes in terms of achieving high performance (Peleg, 2009; Wachelka \& Katz, 1999). Twenty per cent of students with academic anxiety dropped out of school before graduating (Wachelka \& Katz 1999). Therefore, students with higher learning-related anxiety are assumed less likely to persist with e-learning in web-based distance education.

Online interaction also influences successful outcomes in web-based distance education (Moore, 2014). 
Research has examined the role of interaction in web-based distance education, including interactions with the instructor (Swan, Shea, Fredericksen, Pickett, Pelz, \& Maher, 2000), with other learners (Ekwunife-Orakwue \& Teng, 2014), and with the course content (Kuo, Walker, Schroder, \& Belland, 2014). The first type of interaction takes place between the learner and the instructor. Moore (1989) finds that the role of the instructor is very important, especially in web-based distance education, because the instructor provides adequate and individualized responses to each student's needs and interacts with students. According to Moore's (1989) transactional distance theory, psychological and communicational gaps may exist between instructors and students in web-based education because of the physical distance inherent in e-learning environments. Increasing the interactions with the instructor helps decrease social distance and establish a social presence between instructors and students. To achieve these ends, instructors should attempt to have many interactions with students in their e-learning processes (Bouhnik \& Marcus, 2006). The second type of interaction takes place among students. Web-based distance education courses provide web-based tools, such as email, online conferences, instant messaging, and chat rooms, to strengthen the interactions among students. Learners' interactions with one another can help them overcome their isolation in web-based education communities and develop relationships with other learners (Trentin, 1998). In the education process, the third type of interaction, which occurs between learner and the course content, takes place when the learner, with the help of the instructor or the teaching institution, changes his or her understanding, perspectives, or cognitive structures by absorbing new knowledge and combining it with existing knowledge (Bouhnik \& Marcus, 2006).

In previous empirical studies, online interaction and retention are indirectly related and are mediated by student satisfaction (Drouin, 2008; Swan, 2002). Additionally, researchers have shown that interactions with the instructor (Kuo et al., 2014; Swan et al., 2000), with other learners (EkwunifeOrakwue \& Teng, 2014), and with the course content (Ekwunife-Orakwue \& Teng, 2014; Kuo et al., 2014) all relate to successful learning outcomes in online education. In web-based learning settings, instructors must identify communication methods for student-to-student interactions and for studentinstructor interactions. Creating and maintaining interactions is important, as an individual's understanding of knowledge is enriched by social discourse during the learning process. However, online interaction increases the perceived social presence in virtual environments and affects students' retention in web-based distance education (Drouin, 2008). Previous research (Drouin, 2008; Swan, 2002) has suggested an indirect effect of online interaction - primarily as a mediator, not as a moderator. Little research examines the moderating role of online interactions in predicting intention to persist with web-based distance education, especially among students with visual impairment.

Based on previous studies, this study sought to explore whether learning-related anxiety would negatively affect intention to persist with e-learning among students with visual impairment. According to Moore's (1989) transactional distance theory, we sought to explore the influence of transactional distance factors, three types of online interactions, on intention to persist. Learning-related anxiety is inversely related to positive learning outcomes, such as intention to persist. To our knowledge, online interaction has not been used as a moderator variable in the negative relationship between learningrelated anxiety and intention to persist. We expected that online interaction could directly increase intention to persist as well as buffer the strength of the negative relationship between learning-related anxiety and intention to persist. Thus, this study aimed to examine the buffering effect of three online 
interactions as a third variable on the relationship between learning-related anxiety and intention to persist with e-learning.

We specifically hypothesized the following (see the research model in Figure 1):

H1: The independent variable, learning-related anxiety, will negatively affect the dependent variable, intention to persist.

H2: The moderator variable, interactions with the instructor, will buffer the impact of learning-related anxiety on intention to persist.

H3: The moderator variable, interactions with other learners, will buffer the impact of learning-related anxiety on intention to persist.

H4: The moderator variable, interactions with the course content, will buffer the impact of learning-related anxiety on intention to persist.

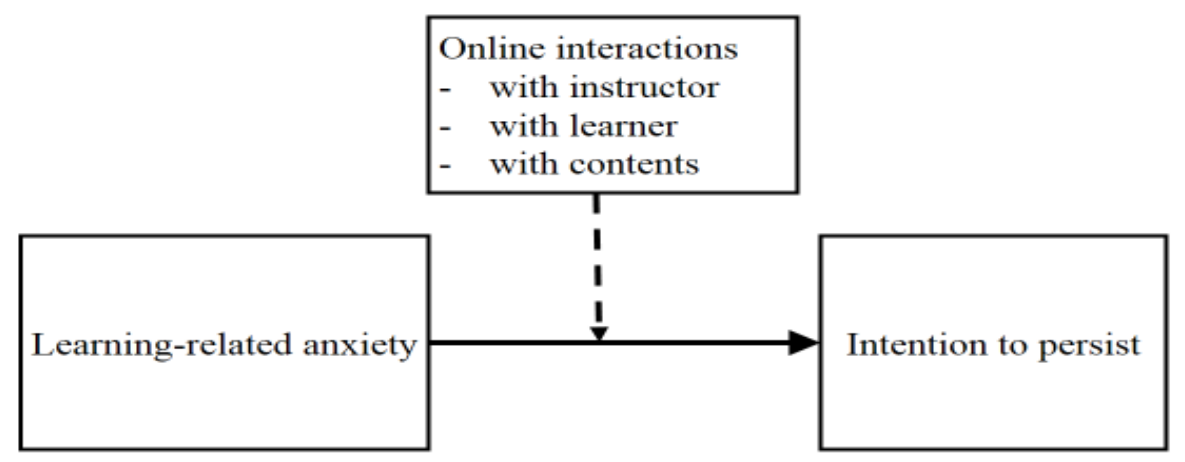

Figure 1. The research model.

\section{Methods}

\section{Procedure}

The data for this study were collected via email or phone survey. Students who wanted to participate but had difficulty marking their responses through email were able to respond to the survey by phone. The data collection was conducted for three weeks from November to December 2012. One hundred and forty-two students with visual impairment who attended one of Korea's cyber universities in Seoul were asked to participate in the study. The institutional review board (IRB) approval issue did not apply to our data collection because the study subjects were exempted from IRB approval based on a 2014 
Korean law on life ethics and safety. One hundred and three students with visual impairment completed the survey, providing an overall response rate of $72.54 \%$.

\section{Participants}

One hundred and three individuals with visual impairment, 70 males (68\%) and 33 females (32\%) with the mean age of 41.29, participated in the study. The participants had enrolled for an average of 4.31 semesters, currently taking an average of 17.71 credits. Of the 103 participants, $73.8 \%(n=76)$ were diagnosed with the first grade of visual impairment, having no light perception. On average, the participants utilized 1.37 assistive technology devices or programs during the process of e-learning. Of the causes of their visual impairment, most participants, over $60 \%$, indicated that their visual impairment had postnatal causes (see Table 1).

Table 1

Participants' Characteristics

\begin{tabular}{|c|c|c|}
\hline & & Frequency (Percent \%) $(n=103)$ \\
\hline \multicolumn{3}{|l|}{ Gender } \\
\hline & Male & $70(68 \%)$ \\
\hline & Female & $33(32 \%)$ \\
\hline Age & & $M=41.29(S D=8.06)$ \\
\hline $\begin{array}{l}\text { The number o } \\
\text { semesters } \\
\text { having spent }\end{array}$ & & $M=4.31(S D=2.11)$ \\
\hline \multicolumn{3}{|l|}{$\begin{array}{l}\text { Grades of } \\
\text { disability }\end{array}$} \\
\hline & $1^{\text {st }}$ (no light perception) & $76(73.8 \%)$ \\
\hline & $\begin{array}{l}2^{\text {nd }} \text { (light perception, correction- } \\
\text { eye sight under .04) }\end{array}$ & $5(4.9 \%)$ \\
\hline & $\begin{array}{l}3^{\text {rd }} \text { (the ability to count fingers, } \\
\text { correction-eye sight under } .8)\end{array}$ & $5(4.9 \%)$ \\
\hline & $4^{\text {th }}$ (correction-eye sight under .1) & $1(1 \%)$ \\
\hline & $5^{\text {th }}$ (correction-eye sight under .2) & $4(3.9 \%)$ \\
\hline & $6^{\text {th }}$ (a visual field restriction) & $12(11.7 \%)$ \\
\hline \multirow{6}{*}{$\begin{array}{l}\text { The cause of } \\
\text { their visual } \\
\text { impairment }\end{array}$} & Ophthalmological disease & $40(38.8 \%)$ \\
\hline & Congenital conditions & $35(34 \%)$ \\
\hline & Traffic accidents & $6(5.8 \%)$ \\
\hline & Other accidents & $6(5.8 \%)$ \\
\hline & Uncertainty & $10(9.7 \%)$ \\
\hline & The others & $6(5.8 \%)$ \\
\hline
\end{tabular}

The number of assistive technology 
devices or

programs

\begin{tabular}{llc} 
(multiple & Screen reader & $60(58.3 \%)$ \\
response & Screen magnifying programs & $32(31.1 \%)$ \\
question) & Braille notetaker & $24(23.3 \%)$ \\
& Scanning programs & $6(5.8 \%)$ \\
& Other devices & $18(17.5 \%)$ \\
\hline $\begin{array}{l}\text { Credits taken } \\
\text { in the current } \\
\text { semester }\end{array}$ & & $M=17.72(S D=3.67)$ \\
\hline
\end{tabular}

\section{Measures}

The demographic characteristics questionnaire consisted of seven items that were designed to obtain the participants' demographic information: age, gender, the number of semesters completed or enrolled in, the number of assistive technology devices or programs used in the process of e-learning, the number of credits taken in the current semester, visual impairment grades, and the cause(s) of visual impairment.

Learning-related anxiety was assessed using a subscale of the Achievement Emotions Questionnaire (AEQ) (Pekrun, Goetz, Frenzel, Barchfeld, \& Perry, 2011), which uses a 5-point Likert scale (1 = completely disagree, $5=$ completely agree) with eleven items - the higher the score, the higher the level of learning-related anxiety. The Korean translated version of the AEQ (Byun, 2011) showed the Cronbach's alpha of .887, and the Cronbach's alpha for our study was .905.

Intention to persist was measured using the six items on the persistence scale that was developed by Shin (2003) in his study of 506 web-based distance education students and was retested in Kim's study (2010) of 973 e-learning students. The Cronbach's alpha was .83 for Shin's (2003) study and .95 for Kim's (2010) study. In this study, the Cronbach's alpha of the scale was .819.

Online interaction was measured using the scale of Bong, Ju, and Park (2006). The interaction scale was based on Moore's (1989) transactional distance theory and consisted of three types of interactions: with the instructor, with other learners, and with the course content. The scale consists of six items, two items per an interaction type, and higher scores indicate higher levels of interaction in web-based distance education settings. Kim (2009) used the scale to study the relationships between interactions and learning outcomes among e-learning students in Korea, and the reliability of the scale was reconfirmed with an alpha coefficient of .80. In the present study, the Cronbach's alpha was .812.

\section{Data Analysis}

The Statistical Package for the Social Sciences (SPSS 21) for Windows was used in all the data analyses. Descriptive information on the study variables and Pearson's correlations were presented to check the assumptions of the multiple regression. Baron and Kenny (1986) suggested the following procedures for the hierarchical regression analysis. The first model included an independent variable and a 
dependent variable. A possible moderator variable was added in the second model. The interactive term of the deviation scores of the independent variable and the moderator variable was inputted in the third model. The significant change in the increment between the second and third models confirms the buffering effect of the possible moderator variable.

\section{Results}

Bivariate correlations of the key study variables - learning-related anxiety, interactions with the instructor, interactions with other learners, interactions with the course content, and intention to persist - are shown in Table 2. We checked the normality and multicollinearity to confirm whether the assumptions for multivariate regression analysis were met. As presented in Table 2, the kurtosis values ranged between -.298 and 1.177, and the skewness values ranged between -.920 and .015 , both of which were considered in the acceptable range of the normality assumption (Curran, West, \& Finch, 1996). In addition, to avoid the problems associated with multicollinearity when using interactive terms, deviation scores were created for the independent variable and possible moderator variables in all the hierarchical moderated multivariate regression analyses by subtracting the mean score from raw scores as a centring method.

The absolute values of Pearson's correlations for the study variables ranged between .038 and .659, that is, below .8. All the variance inflation factors (VIFs) in this study were below 2 (see Tables 3, 4, and 5), and the multicollinearity issue did not exist, as they were all below the critical point of 10 .

Table 2

Bivariate Correlations and Descriptive Statistics for the Study Variables ( $n=103)$

\begin{tabular}{|c|c|c|c|c|c|c|c|c|}
\hline & $M(S D)$ & Kurtosis & Skewness & 1 & 2 & 3 & 4 & 5 \\
\hline $\begin{array}{l}\text { 1. Learning- } \\
\text { related anxiety }\end{array}$ & $27.04(6.90)$ & 1.177 & -.048 & & & & & \\
\hline $\begin{array}{l}\text { 2. Interaction } \\
\text { with instructor }\end{array}$ & $6.74(1.55)$ & .409 & -.344 & $-.444^{* * *}$ & & & & \\
\hline $\begin{array}{l}\text { 3. Interaction } \\
\text { with learner }\end{array}$ & $5.29(1.71)$ & -.298 & .015 & -.148 & $.438^{* *}$ & & & \\
\hline $\begin{array}{l}\text { 4. Interaction } \\
\text { with contents }\end{array}$ & $6.28(1.67)$ & .045 & -.317 & $-.350^{* *}$ & $.659^{* *}$ & $.459^{* *}$ & & \\
\hline $\begin{array}{l}\text { 5. Intention to } \\
\text { persist }\end{array}$ & $25.72(3.00)$ & .811 & -.920 & $-.371^{* *}$ & .185 & -.154 & .038 & \\
\hline
\end{tabular}

${ }^{* *} p<.01,{ }^{*} p<.05$

To examine the study's hypotheses, we performed hierarchical moderated multivariate regression analyses according to Baron and Kenny (1986). The results of the regression analyses, which were performed with three types of interactions as possible moderator variables, are presented in Tables 3 , 4 , and 5 . 


\section{Interactions with the Instructor}

The first model indicated that learning-related anxiety was significantly associated with intention to persist $(\beta=-.371, \mathrm{t}[101]=-4.015, p=.0001)$, which implies that the predictor variable, learning-related anxiety, decreased intention to persist. The first regression model was significant, with $R^{2}=.138, F(1$, $101)=16.116, p=.0001$, and learning-related anxiety accounted for $13.8 \%$ of the variation in intention to persist. In the second model, the possible moderator variable, interactions with the instructor, was added, and the second model was significant $\left(R^{2}=.138, F(2,100)=8.013, p=.001\right)$. Learning-related anxiety was still significant $(\beta=-.360, \mathrm{t}[100]=-3.473, p=.001)$, but interactions with the instructor were not significantly associated with intention to persist $(\beta=.025, \mathrm{t}[100]=.243, p=.808)$; this finding demonstrated that interactions with the instructor did not directly predict intention to persist. In the third model, the interactive term of learning-related anxiety and interactions with the instructor was added. The results of the third model indicated that learning-related anxiety was still significant $(\beta=-$ $.339, \mathrm{t}[99]=-3.303, p=.001)$, but interactions with the instructor were not significant $(\beta=.028, \mathrm{t}[99]$ $=.273, p=.786)$. The interactive term was statistically significant $(\beta=-.185, \mathrm{t}[99]=-2.008, p=.047)$; the third model was statistically significant $\left(R^{2}=.172, F(3,99)=6.848, p=.0001\right)$; and the $R^{2}$ increment from the second model to the third model was statistically significant $\left(\Delta R_{23}{ }^{2}=.034\right)$. This finding confirmed the moderator role of interactions with the instructor when learning-related anxiety negatively affected intention to persist, implying that learning-related anxiety negatively predicted intention to persist (verifying hypothesis 1). Hypothesis 2, i.e., interactions with the instructor will buffer the relationship between learning-related anxiety and intention to persist, was supported by the testing.

Table 3

A Test of Buffering Effect of Interaction with Instructor on the Relationship of Learning-Related Anxiety and Intention to Persist. (n=103)

\begin{tabular}{|c|c|c|c|c|c|c|c|c|c|c|}
\hline Model & Variable & $B$ & $\beta$ & $t$ & $p$ & $R^{2}$ & adj. $R^{2}$ & $\Delta R^{2}$ & $F$ & $\mathrm{VIF}$ \\
\hline 1 & $\begin{array}{l}\text { Learning- } \\
\text { related } \\
\text { anxiety (A) }\end{array}$ & -.161 & -.371 & -4.015 & .0001 & .138 & .129 & .138 & $16.116^{* *}$ & \\
\hline \multirow{2}{*}{2} & $\begin{array}{l}\text { Learning- } \\
\text { related } \\
\text { anxiety (A) }\end{array}$ & -.156 & -.360 & -3.473 & .001 & \multirow{2}{*}{.138} & \multirow{2}{*}{.121} & \multirow{2}{*}{.001} & \multirow{2}{*}{$8.013^{* * *}$} & 1.245 \\
\hline & $\begin{array}{l}\text { Interaction } \\
\text { with } \\
\text { instructor (B) }\end{array}$ & .049 & .025 & .243 & .808 & & & & & 1.245 \\
\hline \multirow{3}{*}{3} & $\begin{array}{l}\text { Learning- } \\
\text { related } \\
\text { anxiety (A) }\end{array}$ & -.147 & -.339 & -3.303 & .001 & \multirow{3}{*}{.172} & \multirow{3}{*}{ 147 } & \multirow{3}{*}{.034} & \multirow{3}{*}{$6.848^{* *}$} & 1.258 \\
\hline & $\begin{array}{l}\text { Interaction } \\
\text { with } \\
\text { instructor (B) }\end{array}$ & .054 & .028 & .273 & .786 & & & & & 1.245 \\
\hline & $A \times B$ & -.044 & -.185 & -2.008 & .047 & & & & & 1.012 \\
\hline
\end{tabular}

${ }^{* *} p<.01,{ }^{*} p<.05 \quad ※$ Dependent variable: Intention to persist 


\section{Interactions with other Learners}

To examine hypothesis 3, we performed the same analyses as those performed for interactions with the instructor (See Table 4). The first model produced the same result: learning-related anxiety was significantly associated with intention to persist. In the second model, another possible moderator variable, interactions with other learners, was added, and the second model was significant $(F(2,100)$ $=11.155, p=.0001)$. Learning-related anxiety was still significant $(\beta=-.403, \mathrm{t}[100]=-4.404, p=.0001)$, and interactions with other learners were significantly associated with intention to persist $(\beta=-.214$, $\mathrm{t}[100]=-2.341, p=.021)$. This finding showed that more interactions with other learners directly predicted a decreased intention to persist. In the third model, the interactive term of learning-related anxiety and interactions with other learners was added, and the results indicated that both learningrelated anxiety $(\beta=-.424, \mathrm{t}[99]=-4.945, p=.0001)$ and interactions with learners $(\beta=-.261, \mathrm{t}[99]=-$ $3.018, p=.003)$ were still significant. The interactive term was statistically significant $(\beta=-.331$, $\mathrm{t}[99]$ $=-3.870, p=.0001)$; the third model was statistically significant $(F(3,99)=13.469, p=.0001)$; and the $R^{2}$ increment from the second model to the third model was statistically significant $\left(\Delta R_{23}{ }^{2}=.107\right)$. These findings appear to confirm the moderating role of interactions with other learners when learningrelated anxiety negatively affected intention to persist. However, the absolute value of the zero-order correlation coefficient between interactions with other learners and intention to persist (.154) was smaller than that of the partial correlation coefficient (.214), and the two had different signs (+/-). As the models shifted, the standardized regression coefficient of learning-related anxiety changed from .371 to -.403 and then -.424 . This finding suggests that the impact of learning-related anxiety on intention to persist will be greater with the inclusion of interactions with other learners (Tabachnick \& Fidell, 2007), that is, that interactions with other learners act as a suppressor variable with a confounding effect on the relationship between learning-related anxiety and intention to persist (Cohen, Cohen, Stephen, \& Aiken, 2002; Koeske, 1998). Using Cohen, Cohen, Stephen, \& Aiken's (2002) calculation, we can reconfirm the confounder role of interactions with other learners between learning-related anxiety and intention to persist as follows: The zero-order correlation coefficient between interactions with other learners and intention to persist is $r=-.154$, which equals the sum of the direct effect of interactions with other learners on intention to persist $(\beta=-.214)$ and the suppression effect $[(\beta=-.403)(r=-.148)=.060]$. That sum was $-.154=-.214+.060$ (see Figure 2$)$, which implies that learning-related anxiety negatively predicts intention to persist (verifying hypothesis 1). However, hypothesis 3, i.e., interactions with other learners will buffer the relationship between learning-related anxiety and intention to persist, was rejected after testing. As shown in Figure 2, the direct effects of learning-related anxiety and interactions with other learners on intention to persist were confirmed.

Table 4

A Test of Buffering Effect of Interaction with Learner on the Relationship of Learning-Related Anxiety and Intention to Persist. $(n=103)$

\begin{tabular}{|l|l|l|l|l|l|l|l|l|l|l|}
\hline \multirow{2}{*}{ Model } & Variable & $B$ & $\beta$ & $t$ & $p$ & $R^{2}$ & adj. $R^{2}$ & $\Delta R^{2}$ & $F$ & $\mathrm{VIF}$ \\
\hline
\end{tabular}




\begin{tabular}{|c|c|c|c|c|c|c|c|c|c|c|}
\hline 1 & $\begin{array}{l}\text { Learning- } \\
\text { related } \\
\text { anxiety (A) }\end{array}$ & -.161 & -.371 & -4.015 & .0001 & .138 & .129 & .138 & $16.116^{* *}$ & \\
\hline \multirow{2}{*}{2} & $\begin{array}{l}\text { Learning- } \\
\text { related } \\
\text { anxiety (A) }\end{array}$ & -.175 & -.403 & -4.404 & .0001 & \multirow{2}{*}{.182} & \multirow{2}{*}{.166} & \multirow{2}{*}{.045} & \multirow{2}{*}{$11.155^{* *}$} & 1.022 \\
\hline & $\begin{array}{l}\text { Interaction } \\
\text { with } \\
\text { learner(B) }\end{array}$ & -.376 & -.214 & -2.341 & .021 & & & & & 1.022 \\
\hline \multirow{3}{*}{3} & $\begin{array}{l}\text { Learning- } \\
\text { related } \\
\text { anxiety (A) }\end{array}$ & -.184 & -.424 & -4.945 & .0001 & \multirow{3}{*}{.290} & \multirow{3}{*}{.268} & \multirow{3}{*}{.107} & \multirow{3}{*}{$13.469^{* * *}$} & 1.027 \\
\hline & $\begin{array}{l}\text { Interaction } \\
\text { with } \\
\text { learner(B) }\end{array}$ & -.458 & -.261 & -3.018 & .003 & & & & & 1.043 \\
\hline & $\mathrm{A} \times \mathrm{B}$ & -.066 & -.331 & -3.870 & .0001 & & & & & 1.022 \\
\hline
\end{tabular}

${ }^{* * *} p<.01,{ }^{*} p<.05 ※$ Dependent variable: Intention to persist

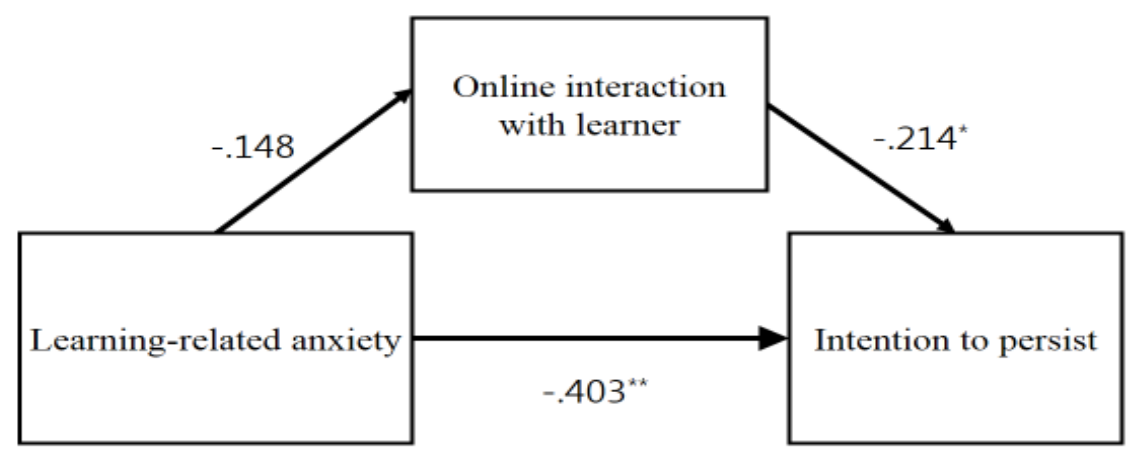

Figure 2. The suppressor role of interaction with learner.

\section{Interactions with the Course Content}

To examine hypothesis 4, we performed the same analyses as those performed for interactions with the instructor and with other learners (see Table 5). The first model indicated the same result: learningrelated anxiety was significantly associated with intention to persist. In the second model, the third possible moderator variable, interactions with the course content, was added, and the second model was significant $(F(2,100)=8.636, p=.0001)$. Learning-related anxiety was still significant $(\beta=-.408$, $\mathrm{t}[100]=-4.136, p=.0001)$, but interactions with the course content were not significantly associated with intention to persist $(\beta=-.105, \mathrm{t}[100]=-1.065, p=.289)$. These findings demonstrated that 
interactions with the course content did not directly predict intention to persist. In the third model, the interactive term of learning-related anxiety and interactions with the course content was added. The results of the third model indicated that learning-related anxiety was still significant $(\beta=-.421, \mathrm{t}[99]=$ -4.495, $p=.0001)$, but interactions with the course content were $\operatorname{not}(\beta=-.122, \mathrm{t}[99]=-1.303, p=.196)$. The interactive term was statistically significant $(\beta=-.305, \mathrm{t}[99]=-3.479, p=.001)$; the third model was statistically significant $(F(3,99)=10.432, p=.0001)$; and the $R^{2}$ increment from the second to the third models was statistically significant $\left(\Delta R_{23}{ }^{2}=.093\right)$. These findings appear to confirm the moderator role of interactions with the course content when learning-related anxiety negatively affected intention to persist. However, the absolute value of the zero-order correlation between interactions with the course content and intention to persist (.038) was smaller than that of the partial correlation coefficient (.122), and the two had different signs (+/-). As the models shifted, the standardized regression coefficient of learning-related anxiety changed from -.371 to -.408 and then to -.421 , which implies that the impact of learning-related anxiety on intention to persist is greater with the inclusion of interactions with the course content (Tabachnick \& Fidell, 2007). These findings suggest that interactions with the course content act as another suppressor variable with a confounding effect on the relationship between learning-related anxiety and intention to persist. Using Cohen et al.'s (2002) calculation, we can reconfirm the confounder role of interactions with the course content between learning-related anxiety and intention to persist as follows: The zero-order correlation coefficient between interactions with the course content and intention to persist is $r=.038$, which equals the sum of the direct effect of interactions with the course content on intention to persist $(\beta=-.105)$ and the suppression effect $[(\beta=-.408)(r=-.350)=.143]$. This sum was .038 $=-.105+.143$ (see Figure 3 ), which implies that learning-related anxiety negatively predicts intention to persist (verifying hypothesis 1). However, hypothesis 4, i.e., interactions with the course content will affect the relationship between learning-related anxiety and intention to persist, was rejected. As shown in Figure 3, the direct effect of learning-related anxiety on intention to persist was confirmed. However, the correlation coefficient between learning-related anxiety and interactions with the course content was significant, which confounded the effect of learning-related anxiety on intention to persist. We suspected that the suppression effect of interactions with the course content would stem from their role as an extraneous variable, which usually occurs prior to an independent variable and a dependent variable in the causal model. The temporal order or causality between learning-related anxiety and interactions with the course content is still in question because interactions with the course content might precede learningrelated anxiety. Interactions with the course content might inflate the effect of learning-related anxiety as an antecedent variable, thus unduly affecting intention to persist.

Table 5

A Test of Buffering Effect of Interaction with Contents on the Relationship of Learning-Related Anxiety and Intention to Persist. (n=103)

\begin{tabular}{|l|l|c|c|c|c|c|c|c|c|l|}
\hline Model & Variable & $B$ & $\beta$ & $t$ & $p$ & $R^{2}$ & adj. $R^{2}$ & $\Delta R^{2}$ & $F$ & VIF \\
\hline 1 & $\begin{array}{l}\text { Learning- } \\
\text { related } \\
\text { anxiety (A) }\end{array}$ & -.161 & -.371 & -4.015 & .0001 & .138 & .129 & .138 & $16.116^{* *}$ & - \\
\hline
\end{tabular}




\begin{tabular}{|c|c|c|c|c|c|c|c|c|c|c|}
\hline \multirow{2}{*}{2} & $\begin{array}{l}\text { Learning- } \\
\text { related } \\
\text { anxiety (A) }\end{array}$ & -.177 & -.408 & -4.136 & .0001 & \multirow{2}{*}{.147} & \multirow{2}{*}{.130} & \multirow{2}{*}{.010} & \multirow{2}{*}{$8.636^{* *}$} & 1.139 \\
\hline & $\begin{array}{l}\text { Interaction } \\
\text { with contents } \\
\text { (B) }\end{array}$ & -.188 & -.105 & -1.065 & .289 & & & & & 1.139 \\
\hline \multirow{3}{*}{3} & $\begin{array}{l}\text { Learning- } \\
\text { related } \\
\text { anxiety (A) }\end{array}$ & -.183 & -.421 & -4.495 & .0001 & \multirow{3}{*}{.147} & \multirow{3}{*}{.217} & \multirow{3}{*}{.093} & \multirow{3}{*}{$10.432^{* *}$} & 1.141 \\
\hline & $\begin{array}{l}\text { Interaction } \\
\text { with contents } \\
\text { (B) }\end{array}$ & -.219 & -.122 & -1.303 & .196. & & & & & 1.142 \\
\hline & $\mathrm{A} \times \mathrm{B}$ & -.058 & -.305 & -3.479 & .001 & & & & & 1.003 \\
\hline
\end{tabular}

${ }^{* * *} p<.01,{ }^{*} p<.05 \%$ Dependent variable: Intention to persist

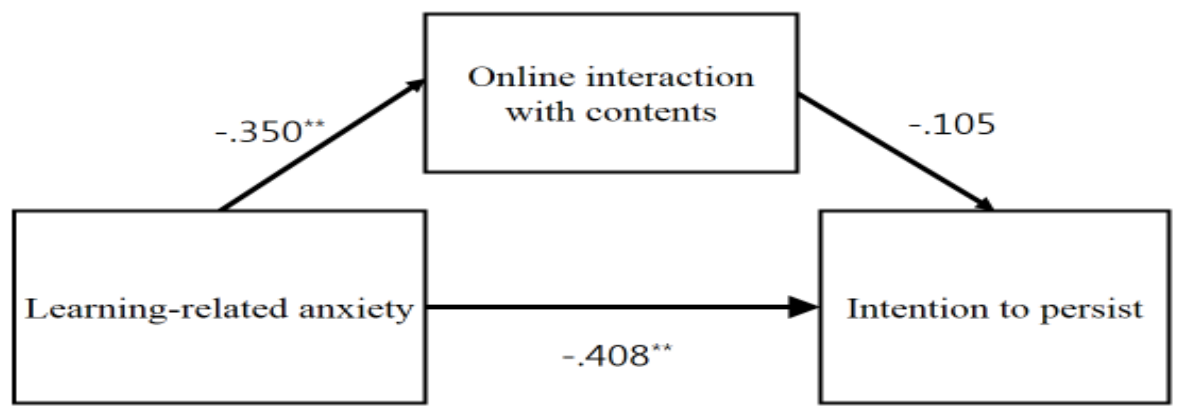

Figure 3. The suppressor role of interaction with contents.

\section{Discussion}

This study sought to explore the relationship between learning-related anxiety and intention to persist with e-learning among students with visual impairment and to examine the buffering effect of online interactions on the relationship between learning-related anxiety and intention to persist with elearning. The multiple regression analyses showed a significant association between learning-related anxiety and intention to persist with e-learning. As expected, students with higher levels of learningrelated anxiety tend to have lower levels of intention to persist with e-learning in web-based distance education. Students with visual impairment particularly experience more learning-related anxiety in the e-learning process compared with their counterparts without visual impairment (Lufi \& Awwad, 2013; Peleg, 2009).

Of the three types of online interactions, only interactions with the instructor had a buffering effect on 
the relationship between learning-related anxiety and intention to persist. This finding supports Drouin's (2008) study results, suggesting that the social presence of the instructor in the virtual environment, developed through interactions between students and instructor, increases student satisfaction with e-learning and may aid in student retention.

By contrast, interactions with other learners have a directly negative effect on intention to persist and play an intensifier role in the relationship between learning-related anxiety and intention to persist. Students with visual impairment may have difficulties maintaining interactions with others in online environments. Online communication requires rapid turn taking in conversation and catching nonverbal cues, which is not easy for students with visual impairment to fully understand because of the limited accessibility of web-based images, flash animations, and mouse-operated controls in elearning settings. Social interactions in e-learning settings appear to be additional escalators of learning-related anxiety, thus interfering with intention to persist with e-learning. Our finding corresponds with Drouin's (2008) proposition that e-learning students do not necessarily have to be satisfied with the social interactions in an e-learning setting to remain enrolled in web-based distance education.

Interactions with the course content have no direct effects on intention to persist, but they might act as an antecedent variable when inflating the impact of learning-related anxiety on intention to persist. In contrast to previous studies (Drouin, 2008; Ekwunife-Orakwue \& Teng, 2014; Kuo et al., 2014; Swan et al., 2000; Swan, 2002) that predicted e-learning outcomes, interactions with the course content did not have a direct effect on intention to persist in our study. In general, students in web-based distance education independently interact with the academic materials during the learning process. However, students with visual impairment encounter barriers to individual interactions with academic materials and course content in e-learning settings. They have difficulties in accessing images, mathematical diagrams, and equations in the interactive format and in converting digital information into an accessible format. Rehabilitation engineering, such as screen readers, Braille notetakers, and other devices, are not always compatible with the latest computers and software, and such gaps hinder students with visual impairment from interacting in e-learning environments. Therefore, interactions with the course content can be a stressor for students with visual impairment because they are uncomfortable with the diverse and new digital contents. Interactions with the course content appear to precede learning-related anxiety as a stressor, aggravating the relationship between learning-related anxiety and intention to persist.

\section{Limitations}

Our study utilized a correlational design with a convenience sample, which may have led to some limitations. Regarding the direction of causation, the cross-sectional data cannot explain the causation of the variables' sequence in a temporal order. Strictly speaking, we sequentially ordered learningrelated anxiety, online interactions, and intention to persist in our research model, but a cross-sectional study cannot reflect the temporal order of these variables. In the future, a longitudinal study is needed to retest the causality of learning-related anxiety and online interactions. With respect to sampling, our convenience sample came from one cyber university in Seoul, Korea. The data did not reflect the general population of those with visual impairments who attend cyber universities. Our data were collected by email and telephone. The potential participants via these two methods may be systematically different; 
the participants who completed the surveys by email may have had good computer skills, whereas those who completed them by telephone may have been less skilled, which may have led to systematic bias. Despite these limitations, our study is a preliminary attempt to draw attention to an understudied area of web-based distance education among students with visual impairment.

\section{Conclusion and Implications}

Our study found that three types of online interactions had different roles in and effects on the elearning process among students with visual impairment. Based on the study findings, we suggest the following implications for e-learning education among students with visual impairment.

\section{Interactions with the Instructor}

According to Moore's (1989) transactional distance theory, instructors and their students need to increase online interactions to strengthen the social presence of the instructors. Instructors should use their expert knowledge to ensure that the learning process is efficient and that course-related interactions occur frequently and in a timely manner (Bouhnik \& Marcus, 2006). Instructors should have student-oriented interactions with students with visual impairment to influence students during the learning process and lead them to continue with their e-learning. In an online classroom, instructors must ensure viable communication methods, such that students with visual impairment are able to participate in the social exchange of information in a virtual environment. Chatting programs that exchange only intrinsic information for them should be applied in e-learning education settings. Instructors should attempt to use direct messages via email or instant messages rather than general messages on bulletin boards for the entire class, which students may overlook (Moore, 2014). Direct messages to students with visual impairment include sending assignment reminders, promoting online class attendance, praising academic outcomes, correcting individual students' course-related misunderstandings, providing course orientation, and checking accommodations.

Students with visual impairment have different needs from those of their counterparts without visual impairment. For example, in online classrooms, they primarily depend on their auditory sense to gain knowledge from lectures. The visual, inaccessible information cannot reach them without the special attention of their instructors. Instructors need to respond to each student individually to meet their personal needs. They also need to prepare reasonable accommodations, perhaps providing the syllabus in advance, along with accessible digital textbooks and class materials, alternative assignments, and extended test times. More frequent interactions help buffer the impact of learning-related anxiety on intention to persist. Interactions with the instructor cover issues associated with course-related information, knowledge building, counselling, adjustment to e-learning, and special services that are appropriate for students with visual impairment.

\section{Interactions with other Students}

In most of the research findings, more frequent interactions among students help to build a sense of community, which can encourage students to persist with e-learning. However, students with visual 
impairment may find computer-mediated communications with other students burdensome because of the inaccessibility of the web-based education setting. Various methods of online interactions, such as e-mail, online conferences, discussion groups, and chat rooms, must be developed and improved, such that students with visual impairment can use them easily and independently. Modern communication technology, such as social networking services, does not provide fully accessible services for those with visual impairment. These gaps hinder them from interacting with other students and creating a sense of community. To facilitate online communications among students with visual impairment, we need to supplement web-accessible communication regulations, which can help decrease the lag between rehabilitation technology and the latest communication technology. Another suggestion is to encourage classmates without visual impairment to use voice messages and larger fonts when they communicate with their counterparts with visual impairment.

\section{Interactions with the Course Content}

In general, students in web-based distance education independently interact with the academic content and administrative services during the e-learning process. Administrative services are very important in providing students with interpersonal services, such as tutorials and counselling, to meet students' needs (Sewart, 1983), especially those of students with visual impairment. These students take online courses to acquire knowledge and skills by interacting with e-learning content, but sometimes, students with visual impairment have difficulties in approaching e-learning systems and spend extra time and energy acquiring knowledge from e-learning content. E-learning systems, which include links, frames, images, editing boxes, check boxes, and radio buttons, are sometimes inadequately designed without considering rehabilitation technology. Reasonable accommodations at an administrative level are crucial in terms of increasing intention to persist with e-learning.

Students with visual impairment face barriers that limit their full understanding of e-learning content because of delays in screen reader operations and the lack of interactive formats on web pages. Screen readers catch the screen information sequentially line by line, which keeps them from acquiring all the screen information at a glance and determining whether it is relevant (Guercio, Stirbens, Williams, \& Haiber, 2011). E-learning content should be summarized for students with visual impairment whenever a web page pops up, and this content should be in an interactive format that they can easily access. The Digital Accessible Information System (Daisy), which provides textual descriptions of images, mathematical diagrams and equations in interactive formats, helps them to interact with e-learning content. When content is converted in Daisy, students can navigate between headings, frames, controls, and links in a systematic and structural manner. The successful e-learning achievement of students with visual impairment depends on whether e-learning contents are presented in accessible formats (Guercio et al., 2011); thus, designing accessible content for these students is critical for their success in elearning and for their intention to persist with e-learning. 


\section{References}

Baron, R. M., \& Kenny, D. A. (1986). The moderator-mediator variable distinction on social psychological research: Conceptual, strategic and statistical conditions. Journal of Personality and Social Psychology, 51(6), 1173-1182.

Bong, M., Ju, Y., \& Park, S. (2006). 사이버가정학습 효과성 분석 방법론 연구 [A study on methodology of analyzing effectiveness of Cyber home study]. Seoul: Korean Education and Research Information Service.

Bouhnik, D., \& Marcus, T. (2006). Interaction in distance-learning courses. Journal of the American Society for Information Science and Technology, 57(3), 299-305.

Byun, J. (2011). The effects of self-consciousness and academic anxiety on college student adjustment, academic achievement. (Unpublished master's thesis). Sungkyunkwan University, Seoul, Korea.

Calvin, J., \& Freeburg, B. (2010). Exploring adult learners' perceptions of technology competence and retention in web-based courses. The Quarterly Review of Distance Education, 11(2), 63-72.

Campbell-Gibson, C. (1991). Changing perceptions of learners and learning at a distance: A review of selected recent research. In Distance Education Symposium: Selected Papers, Part 1. Papers presented at the Second American Symposium on Research in Distance Education: The Pennsylvania State University, May 1991. University Park: The Pennsylvania State University.

Cohen, P., Cohen, J., Stephen, G. W., \& Aiken, L. S. (2002). Applied Multiple Analysis for the Behavioral Sciences (3rd ed.). Hillsdale, NJ: Erlbaum.

Curran, P., West, S., \& Finch, J. (1996). The robustness of test statistics to nonnormality and specification error in confirmatory factor analysis. Psychological Methods, 1(1), 16-29.

Drouin, M. (2008). The relationship between students' perceived sense of community and satisfaction, achievement, and retention in an online course. The Quarterly Review of Distance Education, 9(3), 267-284.

Ekwunife-Orakwue, K., \& Teng, T. (2014). The impact of transactional distance dialogic interactions on student learning outcomes in online and blended environments. Computer \& Education, $78,414-427$

Guercio, A., Stirbens, K., Williams, J., \& Haiber, C. (2011). Addressing challenges in web accessibility for the blind and visually impaired. International Journal of Distance Education Technologies, 9(4), 1-13.

Heiman, T., \& Precel, K. (2003). Students with learning disabilities in higher education: Academic strategies profile. Journal Learning Disabilities, 36, 248-258. 
Higher Education in Korea (2013). Dropout rates. Retrieved from http://www.academyinfo.go.kr/UIPISA/uipnh/unt/ipsrch/UntUntCprsSrchRdviewer.do

Internet World Stats (2014). Top 50 countries with the highest internet penetration rates-2013. Retrieved from http://www.internetworldstats.com/top25.htm

Karamanos, N., \& Gibbs, P. (2012). A model for student adoption of online interactivity. Research in Post-Compulsory Education, 17(3), 321-334.

Kim, J. (2010). Investigating the structural relationship among internal locus of control, selfefficacy, task value and learning outcome in a cyber university. (Unpublished master's thesis). Ewha Womans University, Seoul, Korea.

Kim, N. (2009). The structural relationship among academic motivation, program, organizational support, interaction, flow and learning outcome in cyber education. (Unpublished doctoral disseration). Ewha Womans University, Seoul, Korea.

Koeske, G. F., (1998). Suppression in the study of parenting and adolescent symptoms: Statistical nuisance and nonsense, or scientific explanation? Journal of Social Service Research, 24(1/2), 111-130.

Korean Council for University College Education. (2013). 2013 Guidebook of mentoring services for college students with disabilities. Retrieved from http://doumi.Kcce.or.kr/

Korean Council of Cyber Universities. (2013). Cyber university information. Retrieved from http://www.cuinfo.net/home/entr/univStats.sub.action?gnb=23

Kuo, Y., Walker, A., Schroder, K., \& Belland, B. (2014). Interaction, internet self-efficacy, and selfregulated learning as predictors of student satisfaction in online education courses. Internet and Higher Education, 20, 35-50.

Lufi, D., \& Awwad, A. (2013). Using the Minnesota Multiphasic Personality Inventory-2 to develop a scale to identify test anxiety among students with learning disabilities. Learning Disability Quarterly, 36(4), 242-249.

Lykourentzou, I., Giannoukos, I., Nikolopoulos, V., Mpardis, G., \& Loumos, V. (2009). Dropout prediction in e-learning courses through the combination of machine learning techniques. Computers \& Education, 53(3), 950-965.

Milem, J. F., \& Berger, J. B. (1997). A modified model of college student persistence: Exploring the relationship between Astin's theory of involvement and Tinto's theory of student departure. Journal of College Student Development, 38, 387-400.

Moore, J. (2014). Effects of online interaction and instructor presence on students' satisfaction and success with online undergraduate public relations courses. Journalism \& Mass Communication Educator, 69(3), 271-288. 
Moore, M. G. (2003). From Chautauqua to the virtual university: A century of distance education in the United States (Report No. 393). Columbus, OH: Center on Education and Training for Employment.

Moore, M. G. (1989). Three types of interaction. American Journal of Distance Education, 3(2), 1-6.

Nachmias, R., \& Shany, N. (2002). Learning in virtual courses and its relationship to thinking styles. Journal of Educational Computing Research, 27(3), 315-329.

Oh, Y., \& Lee, S. (2013). A study exploring the relationship between academic stress and academic achievement among students with visual impairments: Evaluation of moderating effects of self-regulated learning ability and academic self-efficacy. Korean Journal of Visual Impairment, 29(2), 45-66.

Park, J. -H., \& Choi, H. J. (2009). Factors influencing adult learners' decision to drop out or persist in online learning. Educational Technology \&Society, 12(4), 207-217

Pekrun, R., Goetz, T., Frenzel, A., Barchfeld, P., \& Perry, R. (2011). Measuring emotions in students' learning and performance: The Achievement Emotions Questionnaire (AEQ). Contemporary Educational Psychology, 36, 36-48.

Peleg, O. (2009). Test anxiety, academic achievement and self-esteem among Arab adolescents with and without learning disabilities. Learning Disability Quarterly, 32, 1-10.

Sewart, D. (1983) Distance teaching: A contradiction in terms? In D. Sewart, D. \& B. Holmberg (Eds.), Distance Education: international perspectives. London: Croom Helm.

Shin, N. (2003). Transactional presence as a critical predictor of success in distance learning. Distance Education, 24(1), 69-86.

Shin, N., \& Chan, J. (2004). Direct and indirect effects of online learning on distance education. British Journal of Educational Technology, 35(3), 275-288.

Stein, D., \& Wheaton, J. (2002). On-line learning communities and higher education: Factors supporting collaborative knowledge-building (Research Report). Kent, OH: Research Center on Educational Technology.

Swan, K. (2002). Building learning communities in online courses: The importance of interaction. Education, Communication and Information, 2(1), 23-49

Swan, K., Shea, P., Fredericksen, E., Pickett, A., Pelz, W., \& Maher, G. (2000). Building knowledge building communities: Consistency, contact, and communication in the virtual classroom. Journal of Educational Computing Research, 23, 389-413.

Tabachnick, B. G., \& Fidell, L. S. (2007). Using Multivariate Statistics (5th ed.). New York: Allyn \& Bacon. 
Trentin, G. (1998). Computer conferencing systems as seen by a designer of online courses. Educational Technology, 38(3), 36-43.

Wachelka, D., \& Katz, R. C. (1999). Reducing test anxiety and improving academic self-esteem in high school and college students with learning disabilities. Journal of Behavior Therapy, 30, 191198.

\section{Athabasca \\ University}

(c) 